\title{
DINÂMICA ESPAÇO-TEMPORAL DA PAISAGEM DE MIRASSOL D'OESTE/MATO GROSSO, BRASIL
}

\author{
Tiago Ferrarezi Dassoller ${ }^{1}$ \\ Miriam Raquel da Silva Miranda ${ }^{2}$ \\ Sandra Mara Alves da Silva Neves ${ }^{3}$
}

\begin{abstract}
Resumo: O objetivo deste estudo é analisar a dinâmica espaço-temporal da cobertura vegetal e do uso da terra das paisagens do município de Mirassol D’Oeste, Mato Grosso, avaliando a pressão antrópica. Para execução do estudo foram utilizadas as Geotecnologias e aplicado o Índice de Pressão Antrópica para avaliação do estado de conservação da paisagem municipal. Os resultados indicaram alterações em todas as classes durante os 29 anos investigados, com redução de 27,20\% da Savana Florestada, que esteve relacionada com o aumento de 14,58\% da Pastagem; crescimento de 10,64\% da área de agricultura; e o aumento da Floresta Aluvial de 1984 a 1993, seguido de queda de $0,25 \%$ no ano de 2003 e posterior aumento de $0,71 \%$ em 2013. Os resultados do Índice de Pressão Antrópica demonstraram que a paisagem do município de Mirassol D’Oeste encontra-se em estado regular de conservação. As análises realizadas permitiram concluir que o aumento da supressão da vegetação natural, com exceção da Floresta Aluvial, foi em função da inserção da Pastagem e da Agricultura, sendo essas as principais pressões sobre o ambiente.
\end{abstract}

Palavras-chave: Uso e cobertura da terra; Geotecnologias; Sensoriamento remoto; Desmatamento; Amazônia

\section{SPATIO-TEMPORAL DYNAMICS OF LANDSCAPE OF MIRASSOL D'OESTE/MATO GROSSO, BRAZIL}

\begin{abstract}
The aim of this study is to analyze the spatio-temporal dynamics of vegetation cover and land use of the sights of the city of Mirassol D'Oeste, Mato Grosso, assessing the anthropogenic pressure. To carry out the study, the Geotechnologies were used and the Anthropic Pressure Index was applied to evaluate the conservation status of the municipal landscape. The results indicate changes in all classes during the 29 years investigated, with $27.20 \%$ reduction of forested Savannah, which was related with the increase of 14.58 percent of grazing; growth of $10.64 \%$ of the agricultural area; alluvial Forest and of 1984 to 1993 , followed by a fall of $0.25 \%$ in the year 2003 and subsequent increase of $0.71 \%$ in 2013 . The results of the Anthropogenic Pressure Index showed that the landscape of the municipality of Mirassol D'Oeste is in a regular state of conservation. The analysis made it possible to conclude that the increased suppression of natural vegetation, with the exception of the alluvial Forest, was due to the insertion of grazing and agriculture, the main pressures on the environment.
\end{abstract}

Keywords: Use and land cover; Geotechnology; Remote sensing; Deforestation; Amazonia

\footnotetext{
${ }^{1}$ Graduado em Ciências Biológicas e Mestre em Biodiversidade e Agroecossistemas Amazônicos pela UNEMAT. Email: mgmdassoller@hotmail.com

${ }^{2}$ Graduada em Licenciatura em Geografia e Mestre em Ambiente e Sistemas de Produçao Agrícola pela UNEMAT. Email: miriamraquel18@gmail.com

${ }^{3}$ Professora adjunta do Departamento de Geografia e Pós-Graduação em Geografia da UNEMAT. Email: ssneves@unemat.br
} 


\section{DINÁMICA ESPACIO-TEMPORAL DEL PAISAJE DE MIRASSOL D'OESTE/MATO GROSSO, BRASIL}

Resumen: El objetivo de este estudio es analizar la dinámica espacio-temporal de la vegetación cubierta y uso del suelo de los lugares de la ciudad de Mirassol D'Oeste, Mato Grosso, evaluación de la presión antropogénica. Para la ejecución del estudio se utilizaron las Geotecnologías y se aplicó el Índice de Presión Antrópica para evaluar el estado de conservación del paisaje municipal. Los resultados indican cambios en todas las clases durante los 29 años investigados, con reducción de $27.20 \%$ de sabana boscosa, que estuvo relacionado con el aumento del 14,58 por ciento de pastoreo; crecimiento de $10.64 \%$ de la superficie agrícola; Bosque aluvial y de 1984 a 1993, seguido por una caída de 0,25\% en el año 2003 y subsiguiente aumento del 0,71\% em 2013. Los resultados del Índice de Presión Antrópica demostraron que el paisaje del municipio de Mirassol D'Oeste se encuentra en estado regular de conservación. El análisis permitió concluir que la mayor supresión de la vegetación natural, a excepción del bosque aluvial, fue debido a la inserción del pastoreo y la agricultura, las principales presiones sobre el medio ambiente.

Palabras clave: Uso y de la tierra cubierta; Geotecnologia; Teledetección; Deforestación; Amazonia

\section{INTRODUÇÃO}

Aproximadamente um terço da superfície terrestre é coberta por florestas (FAO, 2011), deste total, sete por cento são de Florestas tropicais que concentram metade da biodiversidade do planeta (RAVIKANTH et al.,2000). Dentre as Florestas tropicais destaca-se a Amazônica presente em 10 estados brasileiros, totalizando aproximadamente 5 milhões de quilômetros quadrados, sendo sua maioria de domínio florestal contínuo (AB' SABER, 2005) que contribuem com significativos benefícios para o planeta em relação a preservação de espécies, de solos e do clima (IGLIORI, 2006).

Segundo Alencar et al. (2004) a ocupação da Amazônia, através do modelo tradicional, tem elevado significativamente o desmatamento. Fenômeno este de origem extremamente complexa e que de acordo com Fearnside (2003), Alencar et al. (2004) e Laurance et al. (2004) está estritamente vinculado as políticas públicas de ocupação e desenvolvimento regional, tais como especulação de terra ao longo das estradas, crescimento das cidades, aumento da pecuária bovina, exploração madeireira, agricultura familiar no início da ocupação e atualmente a agricultura mecanizada, vinculada principalmente a soja, algodão e cana-de-açúcar.

Bohrer (2000) descreve que os usos atuais da terra podem determinar a exclusão em curto prazo da aptidão para outros tipos de utilização futura, assim as condições socioeconômicas influenciarão na análise dos níveis de insumos a serem incorporados ao 
sistema produtivo. Cocco et al. (2015) e Neves et al. (2017) discorrem que quanto mais elevados forem as degradações ao ambiente, maiores serão os desequilíbrios ecológicos e, por consequência, maiores serão as alterações da paisagem, afetando a fauna e flora dos biomas. Desta forma faz-se necessário que a cobertura vegetal e do uso da terra no município de Mirassol D’Oeste, Mato Grosso seja reavaliado periodicamente, devido às novas evidências científicas, inovações tecnológicas e mudanças na realidade socioeconômica regional, no intuito de se evitar a degradação dos componentes de suas paisagens.

Os processos mencionados são responsáveis pela acentuada mudança da paisagem, através da antropização da cobertura vegetal via inserção de usos da terra que resultam na excessiva fragmentação, perda de biodiversidade e empobrecimento de solos, evidenciando a necessidade de constante monitoramento das paisagens por meio da investigação da dinâmica de uso da terra e da cobertura vegetal (VITOUSEK et al., 1997 e MARTORANO et al., 2009). As representações cartográficas temporais possibilitam este monitoramento, assim como, a avaliação dos desdobramentos derivados das decisões tomadas pela sociedade no que se refere ao crescimento econômico e à exploração dos elementos naturais (BENEDETTI, 2010).

Segundo Seabra e Cruz (2013) este crescimento econômico implica em alterações nos componentes ambientais, o que confere elevada importância aos mapeamentos de cobertura e uso da terra, principalmente quando é preciso efetuar estudos para compreender a paisagem, termo este que Bertrand (2004) conceituou como sendo uma parcela do espaço, que resulta da relação mútua e dinâmica dos atributos físicos, biológicos e antrópicos que a compõem. Neste contexto, é imprescindível entender as ações e as intervenções que foram realizadas pela sociedade no passado, pois estas mudanças influenciam os processos atuais, alcançando com isto papel essencial na organização do espaço.

O sensoriamento remoto desponta como uma importante ferramenta para análise ambiental seja para o monitoramento e detecção de mudanças ou para o mapeamento do espaço geográfico, contribuindo significativamente em processos decisivos para a gestão, planejamento (ROSA, 2007), e para análise das transformações antrópicas realizadas na paisagem. As ações antrópicas são as principais responsáveis por mudanças na paisagem, as quais ocorrem principalmente na alteração de áreas de vegetação para alguma forma de uso da terra. Neste contexto uma das metodologias utilizadas para avaliar as mudanças da paisagem é o Índice de Transformação Antrópica (ITA), o qual foi proposto por Lémechev (1982) e modificado por Mateo (1991). Segundo Cebalhos et al. (2017) a degradação ambiental é 
geralmente acarretada pela pressão derivada do crescimento populacional e econômico, associada à inexistência de uma política de planejamento e gestão dos elementos naturais constituintes da paisagem. Isto requer uma série de atividades consideradas essenciais para encontrar os caminhos do desenvolvimento sustentável e o manejo adequados recursos ainda existentes (CUNHA e GUERRA, 2003).

O município de Mirassol D’Oeste está inserido na região sudoeste mato-grossense de planejamento (MATO GROSSO, 2012), sendo que 79,20\% de sua extensão territorial está situado no bioma Amazônico e 20,80\% no bioma Pantanal, o que confere elevada importância e singularidade a biodiversidade da região. Carniello et al. (2010) apontaram que a cobertura vegetal desta unidade municipal é extremamente significativa, pois confluem particularidades vegetais remanescentes de Cerrado (sensu lato), também sob ação do Pantanal, e ainda, com existência de fragmentos de Floresta Amazônica, com áreas de ecótonos suscetíveis a grande pressão antrópica, ocasionada pela ocupação e uso da terra.

Nessa ótica, o objetivo deste trabalho é analisar a dinâmica espaço-temporal da cobertura vegetal e do uso da terra das paisagens do município de Mirassol D’Oeste, Mato Grosso, avaliando a pressão antrópica nas mesmas.

\section{DESENVOLVIMENTO}

\section{Material e Métodos}

O município de Mirassol D’Oeste integra a região sudoeste de planejamento, com área territorial de 1.076,358 km² (Figura 1). Está situado entre as coordenadas 15³0’00” a

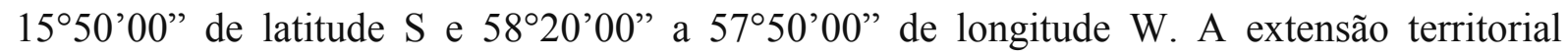
municipal encontra-se distribuída nas bacias dos rios Jauru (36,38\%) e Cabaçal $(35,40 \%)$ e do Córrego Padre Inácio $(28,22 \%)$. 
Figura 1. Município de Mirassol D’Oeste no contexto da região sudoeste mato-grossense de

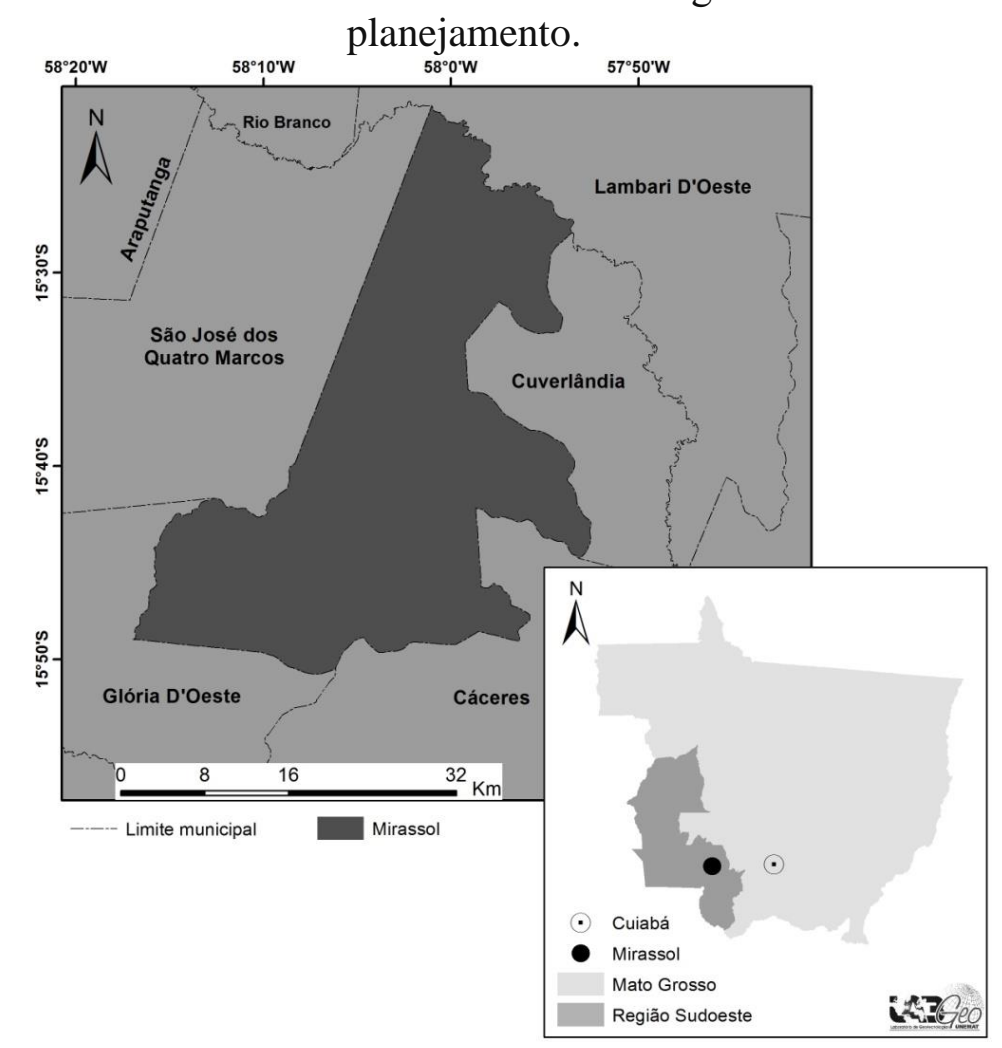

Fonte: LabGeo, 2017.

A população municipal totaliza 25.299 habitantes, sendo que 21.470 residem na zona urbana e 3.829 na rural (IBGE, 2013). De acordo com o Atlas de Desenvolvimento Humano o Índice de Desenvolvimento Humano (IDH-M) do município é de 0,704, abaixo do IDH do Estado, que é de 0,725 e do Brasil que é de 0,730 (PNUD, 2013).

O clima é do tipo Tropical quente e úmido, com inverno seco (Awa). A temperatura média mensal mais elevada é de $28{ }^{\circ} \mathrm{C}$ e média mensal mais baixa de $23{ }^{\circ} \mathrm{C}$. A precipitação anual é de 1500 mm (MATO GROSSO, 2009).

O relevo é formado pela Depressão do rio Paraguai, calha do Jauru, explicitamente na porção que alcança os limites entre as bacias Platina e Amazônica (BRASIL, 1982). As classes de solos presentes são: Neossolos Litólicos Distróficos e Argissolo VermelhoAmarelo Distrófico. A vegetação remanescente compreende principalmente Florestas Estacionais Submontanas (MATO GROSSO, 2009), apresentando também Savana Florestada e áreas de tensão ecológica onde confluem características do bioma amazônico e do cerrado. 


\section{Procedimentos metodológicos}

Para realização da análise espaço-temporal da paisagem utilizou-se as imagens orbitais dos satélites Landsat 5, sensor Thematic Mapper (TM), disponibilizadas gratuitamente pelo Instituto Nacional de Pesquisas Espaciais - INPE; e Landsat 8, sensor Operational Land Imager (OLI), disponibilizada gratuitamente no sítio do Serviço Geológico Americano - SGA (Tabela 1). As imagens adquiridas são do mesmo período sazonal (seco), devido à menor ocorrência de nuvens na cena, e correspondem ao período de vinte e nove anos.

Tabela 1. Características das imagens dos satélites Landsat 5 e 8.

\begin{tabular}{lllccc}
\hline Satélite/sensor & \multicolumn{1}{c}{ Órbita/Ponto } & Bandas & Resolução & Data & Fonte \\
\hline Landsat 5/TM & 227 e 228/71 & 3,4 e 5 & $30 \mathrm{~m}$ & $13 / 08 / 1984$ & INPE \\
Landsat 5/TM & 227 e 228/71 & 3,4 e 5 & $30 \mathrm{~m}$ & $21 / 06 / 1993$ & INPE \\
Landsat 5/TM & 227 e 228/71 & 3 , 4 e 5 & $30 \mathrm{~m}$ & $17 / 06 / 2003$ & INPE \\
Landsat 8/OLI & $228 / 71$ & 4,5 e 6 & $30 \mathrm{~m}$ & $30 / 07 / 2013$ & SGA \\
\hline
\end{tabular}

Fonte: Os Autores, 2017.

Foi efetuada a transformação das imagens do formato TIF para o GRIB no módulo Impima do Spring e em seguida a correção geométrica (registro), exceto para as bandas do Landsat 8, através do método tela-a-tela, utilizando como referência o mosaico de imagens Landsat ortorretificadas disponibilizado pela NASA (TUCKER et al., 2004). Foram selecionados 12 pontos de controle, obedecendo a uma distribuição uniforme destes por toda a superfície da imagem a ser registrada.

Após o registro no Sistema de Processamento de Informações Georreferenciadas SPRING do INPE (CÂMARA et al., 1996) as imagens foram mosaicadas e recortadas pela área de estudo, utilizando como máscara a base cartográfica digital do município de Mirassol D’Oeste, visando economia de tempo nas etapas do processamento.

Para elaboração dos mapas realizou-se o processo de segmentação, que compartimenta a imagem em regiões homogêneas a partir do método de crescimento de regiões, aplicando-se nas imagens Landsat 5 os valores de10 para similaridade e 10 para área, pois os mesmos apresentaram bons resultados no detalhamento das feições, enquanto que no Landsat 8 utilizou-se 2400/800, valores estes obtidos mediante tentativas para a obtenção de um detalhamento satisfatório dos alvos registrados na imagem. A diferença entre os valores de similaridade e área ocorre devido a imagem do Landsat 8 ser 16 bits, o que representa o dobro dos bits das imagens do outro satélite Landsat utilizado. 
Para a classificação foi adotado o método supervisionado, o qual necessita de um conhecimento prévio das feições ocorrentes na área de estudo, pois são coletadas amostras das classes de interesse (Treinamento). Por este motivo realizou-se dois trabalhos de campo no município, o primeiro foi feito em outubro de 2013 e o segundo em fevereiro de 2014, os quais consistiam em percorrer a área estudada coletando pontos através de GPS e adquirindo fotos dos locais onde os pontos foram retirados. Estes trabalhos de campo permitiram classificar de forma coerente às feições espectrais da área de estudo.

Na classificação foi selecionado o algoritmo Bhattacharya, que de acordo com Jensen (1996) e Lima et al. (2006) trata-se de uma distância que mede a separabilidade estatística entre um par de classes espectrais, calculada através da distância média entre as distribuições de probabilidades destas classes, efetua-se então a análise do desempenho das mesmas. $\mathrm{O}$ limiar de aceitação utilizado foi o de 99,9\%, pois ele apresenta maior rigidez para a classificação.

As classes mapeadas foram definidas a partir de pesquisas junto aos relatórios do Projeto de Conservação e Utilização Sustentável da Diversidade Biológica Brasileira PROBIO (BRASIL, 2004) e do manual técnico para vegetação e uso da terra (IBGE, 2012).

Com a finalidade de verificar a confiabilidade do mapa gerado no Spring foi calculado o coeficiente Kappa, o qual é dado por:

$$
K=\frac{n \sum_{i=1}^{c} x_{i i}-\sum_{i=1}^{c} x_{i+} x_{+i}}{n^{2}-\sum_{i=1}^{c} x_{i+} x_{+i}}
$$

em que:

$\mathrm{n}=$ número total de pixels amostrados

xii= número de pixels da linha i e da coluna i da matriz de confusão;

$\mathrm{c}=$ número total de classes;

$\mathrm{xi}+=$ número total de pixels da linha i; e

$\mathrm{x}+\mathrm{i}=$ número total de pixels da coluna $\mathrm{i}$.

Este índice considera a proporção de amostras corretamente classificadas, correspondentes à razão entre a soma da diagonal principal da matriz de erros e a soma de todos os elementos dessa matriz, representadas pelo número total da amostra, tendo como referência o número total de classes (COHEN, 1960). Na tabela 02 é apresentada a qualidade da classificação de acordo com os valores encontrados no Índice Kappa (LANDIS e KOCH, 1977). 
Tabela 02. Qualidade da classificação associada aos valores do Índice Kappa

\begin{tabular}{cc}
\hline Valor de Kappa & Qualidade do Mapa temático \\
\hline$<0,00$ & Péssima \\
$0,00-0,20$ & Ruim \\
$0,20-0,40$ & Razoável \\
$0,40-0,60$ & Boa \\
$0,60-0,80$ & Muito Boa \\
$0,80-1,00$ & Excelente \\
\hline
\end{tabular}

Fonte: Landis e Koch (1977)

As imagens classificadas foram convertidas para o formato shapefile e exportadas para serem editadas no módulo ArcMap do ArcGis, versão 9.2 (ESRI, 2007). Após a finalização da edição, as classes de cobertura vegetal e uso da terra constituintes das paisagens da área de estudo foram quantificadas, através da calculadora de atributos do ArcGis.

A análise multi-temporal foi realizada através da avaliação da dinâmica das classes ao longo dos 29 anos, cartografada nos mapas temáticos gerados e nos valores apresentados pelas classes de cobertura vegetal e uso da terra das paisagens do município de estudo.

O ITA foi calculado mediante os valores de área (\%) obtidos através das classes temáticas de uso da terra e cobertura vegetal quantificadas e mapeadas, sendo encontrado pela seguinte equação:

$$
\mathrm{ITA}=\sum(\% \text { uso } \times \text { peso }) / 100
$$

onde:

Uso: área em valores percentuais da classe de cobertura vegetal e uso da terra;

Peso: valores atribuídos aos diferentes tipos de cobertura vegetal e usos da terra quanto ao grau de alteração antrópica, que varia de 1 a 10, onde 10 indica as maiores pressões.

Desta maneira foram definidos valores para o peso de cada classe de uso da terra e cobertura vegetal de acordo com sua contribuição na alteração da paisagem. O peso de cada classe foi obtido por meio da técnica "Delphi", na qual é realizada uma consulta sistemática a diversos pesquisadores com domínio da temática, permitindo desta forma chegar ao consenso sobre o grau de modificação da paisagem (SCHWENK e CRUZ, 2008). Os pesos de cada classe de uso da terra e cobertura vegetal são apresentados na tabela 03.

Tabela 03. Categorias, classes e pesos das classes de cobertura vegetal e usos da terra do ITA.

\begin{tabular}{ccc}
\hline Categoria & Classes temáticas & Peso \\
\hline Usos da terra & Agricultura & 8
\end{tabular}




\begin{tabular}{llc} 
& Influência Urbana & 9,7 \\
& Pastagem & 5,5 \\
& Reflorestamento & 1 \\
\hline \multirow{2}{*}{ Cobertura } & Floresta Aluvial & 1 \\
vegetal & Floresta Estacional Decidual Submontana & 2 \\
& Savana Florestada & 1 \\
\hline Água & Água & 2 \\
\hline \multicolumn{2}{c}{ Fonte: Os Autores, 2017. }
\end{tabular}

Segundo Cruz et al. (1998) a classificação das bacias em relação a carga antrópica pode ser feita em relação ao quartis: pouco degradado (0 a 2,5); regular (2,5 a 5); degradado (5 a $7,5)$ e muito degradado (7,5 a 10).

Para finalizar realizou-se uma análise de regressão para averiguar a relação do ITA ao longo do tempo. Esta análise objetiva a obtenção de uma equação que explique a relação entre uma variável resposta e uma ou duas variáveis explicativas permitindo realizar predições da variável de interesse (GUIMARÃES, 2008). Nesse sentido realizou-se previsões a cada 10 anos até o ano 2050, a fim de verificar qual será o estado de atropização do município de Mirassol D’Oeste até 2050.

\section{Resultados e Discussão}

O resultado do índice Kappa para as classificações realizadas nos anos de 1984, 1993, 2003 e 2013 foram de 0,77;0,82;0,79 e 0,99, respectivamente, que corresponderam as qualidades das classificações como de muito boa a excelente, indicando que as classificações alcançaram resultados satisfatórios.

De acordo com Jansen (2002) as alterações na cobertura e uso da terra acontecem de duas maneiras, a primeira é a mudança de uma categoria para outra, ou seja, a conversão de floresta para pastagem. E a segunda se relaciona mais ao manejo da área, sendo então a mudança dentro de uma categoria, por exemplo, quando uma área passa de campos agrícolas para agricultura irrigada. Neste contexto, verificou-se que no município de Mirassol D’Oeste ocorreu apenas à mudança de uma classe temática para outra de cobertura e uso da terra.

Foram identificadas, mapeadas e quantificadas três classes de cobertura vegetal, quatro de uso da terra e uma de massa d'água no município de Mirassol D’Oeste (Tabela 4). 
Tabela 04. Classes de cobertura vegetal e uso da terra no município de Mirassol D’Oeste/MT, nos anos de 1984, 1993, 2003 e 2013

\begin{tabular}{|c|c|c|c|c|c|c|c|c|}
\hline \multirow[b]{2}{*}{ Classes temáticas } & \multicolumn{2}{|l|}{1984} & \multicolumn{2}{|l|}{1993} & \multicolumn{2}{|l|}{2003} & \multicolumn{2}{|l|}{2013} \\
\hline & $\begin{array}{l}\text { Área } \\
\left(\mathbf{k m}^{2}\right)\end{array}$ & $\%$ & $\begin{array}{l}\text { Área } \\
\left(\mathbf{k m}^{2}\right)\end{array}$ & $\%$ & $\begin{array}{l}\text { Área } \\
\left(\mathbf{k m}^{2}\right)\end{array}$ & $\%$ & $\begin{array}{l}\text { Área } \\
\left(\mathbf{k m}^{2}\right)\end{array}$ & $\%$ \\
\hline Floresta Aluvial & 34,772 & 3,23 & 93,407 & 8,68 & 90,690 & 8,43 & 98,304 & 9,13 \\
\hline Savana Florestada & 397,887 & 36,97 & 224,471 & 20,85 & 132,881 & 12,35 & 105,152 & 9,77 \\
\hline $\begin{array}{l}\text { Decidual } \\
\text { Submontana }\end{array}$ & 116,713 & 10,84 & 87,660 & 8,14 & 77,608 & 7,21 & 65,050 & 6,04 \\
\hline Reflorestamento & - & - & - & - & - & - & 9,610 & 0,89 \\
\hline Agricultura & 16,794 & 1,56 & 33,919 & 3,15 & 21,835 & 2,03 & 131,312 & 12,20 \\
\hline Pastagem & 502,240 & 46,66 & 626,486 & 58,20 & 743,075 & 69,04 & 659,138 & 61,24 \\
\hline Influência Urbana & 4,258 & 0,40 & 6,419 & 0,60 & 6,427 & 0,60 & 6,924 & 0,64 \\
\hline Massas d’Água & 3,695 & 0,34 & 3,997 & 0,37 & 3,841 & 0,36 & 0,868 & 0,008 \\
\hline Total & 1076,358 & 100 & 1076,358 & 100 & 1076,358 & 100 & 1076,358 & 100 \\
\hline
\end{tabular}

As classes que apresentaram maior dinâmica no ano de 1984 foram a Pastagem, a Savana Florestada e a Floresta Estacional Decidual Submontana; em 1993 a Pastagem, a Savana Florestada e a Floresta Aluvial; em 2003 a Pastagem, a Floresta Aluvial e a Savana Florestada; e em 2013 a Pastagem, a Agricultura, a Savana Florestada e a Floresta Aluvial.

A classe Floresta Estacional Decidual Submontana diminuiu no decorrer dos anos estudados. Entre os anos de 1984 a 1993 sua área decresceu 2,70\%, nos anos seguintes até 2003 a redução foi mantida, no entanto com apenas $0,93 \%$ em relação a 1993. No ano de 2013 a supressão desta formação vegetal continuou sendo constatada uma queda de 1,17\% quando comparada com a área ocupada em 2003.

Constatou-se que no decorrer dos anos estudados houve constante supressão da classe Floresta Estacional Decidual Submontana na área de estudo, pois a comparação da área ocupada no ano de 1984 com a de e 2013 evidencia que a formação foi suprimida em aproximadamente 40\%, até o ano de 2003 esta redução esteve relacionada principalmente ao aumento da pastagem, enquanto que no ano de 2013 o principal responsável foi a expansão da agricultura. Rivero et al. (2009) corroboram afirmando em seu trabalho que as principais causas da supressão da vegetação nativa na Amazônia brasileira são a pastagem, agricultura de larga escala e agricultura de corte e queima.

A classe Savana Florestada foi a mais afetada pela ação antrópica, realizada através da expansão de atividades de maior presença no estado de Mato Grosso (pastagem e agricultura). Entre os anos de 1984 e 1993 foram nítidos os efeitos negativos da pressão antrópica na área, pois constatou-se uma elevada redução de sua extensão territorial $(16,12 \%)$. Entre os anos de 1993, 2003 e 2013 se manteve a redução da classe, entretanto os valores são menores, sendo 
eles 8,51\% entre os primeiros anos e 2,57\% entre os últimos (Figura 2).

Houve supressão da Savana Florestada entre 2003 e 2013, porém se comparados às ocorridas nos anos anteriores o percentual foi baixo, o que pode ser atribuído segundo Machado et al. (2004), ao fato de a Savana Florestada ser do ponto de vista biológico, a mais rica Savana do mundo, possuindo muitas espécies endêmicas, ou seja, espécies que ocorrem apenas neste habitat, o que significa que a sua supressão represente a perca de espécies raras e muitas vezes nem estudadas ainda.

A classe Floresta Aluvial no decorrer dos anos estudados aumentou 5,90\%, possivelmente explicado pela quantidade de vegetação não explorada que não foi distinguida da Floresta Aluvial, fato este que com o decorrer dos anos e com o elevado desmatamento foi se tornando cada vez mais evidente, possibilitando com isto a delimitação e classificação desta classe.

Juntamente com a diminuição da vegetação no município ocorreu a fragmentação desordenada da mesma, que acarretou desequilíbrios gravíssimos, distanciando cada vez mais o equilíbrio dinâmico das paisagens, prejudicando o solo, a diversidade biológica, os recursos hídricos e o meio ambiente como um todo (CABACINHA et al., 2010). 
Figura 2. Cobertura vegetal e uso da terra do município de Mirassol D’Oeste/MT - Brasil, nos anos de 1984, 1993, 2003 e 2013.
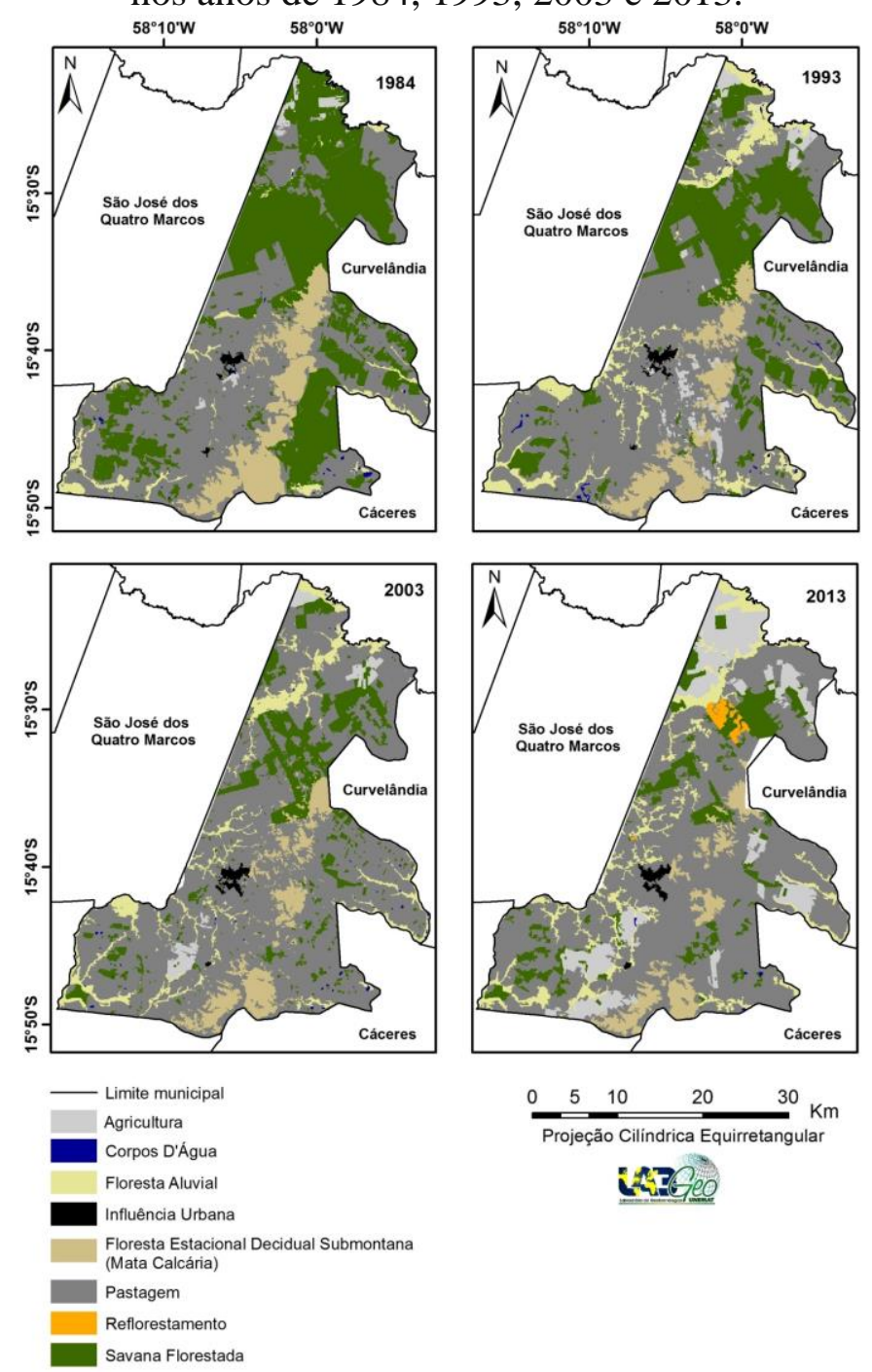

istageo

Fonte: LabGeo, 2017.

O modelo tradicional de ocupação do estado de Mato Grosso, incentivado por diversos programas de desenvolvimento foi responsável pelas elevadas taxas de desmatamento (MARGULIS, 2003). Em Mirassol D’Oeste, assim como em diversos municípios matogrossenses contidos no bioma Amazônia, inicialmente realizava-se a exploração da madeira, sendo posteriormente utilizado o fogo e em seguida a implantação da pastagem para a pecuária de corte.

Os dados do censo agropecuário 2006 (IBGE, 2008) corroboram com os resultados encontrados por este estudo referente à expansão da classe Pastagem verificada em Mirassol D’Oeste (Tabela 4). Após a emancipação municipal, no ano de 1976, houve crescimento da área ocupada pela Pastagem no município, chegando a ocupar no ano 1984 cerca de 46,66\% 
da extensão territorial municipal, decorrente do modelo de ocupação fomentado na época e pela pouca ou inexistente fiscalização ambiental. Nas décadas de 1993 e 2003 houve aumento desta classe, sendo de $11,54 \%$ e 10,83\%, respectivamente. No ano de 2013 a classe diminuiu $7,80 \%$.

Maeda et al. (2008) realizaram uma análise das transformações da Floresta Amazônica em áreas agrícolas na bacia do rio Suia-Miçu/MT, entre os anos de 1973 e 2005, e concluíram que no decorrer de 32 anos 38,4\% de área com cobertura vegetal foi convertida para uso agrícola, sendo a maior parte representada pela pastagem. Pessoa et al. (2013) ao proceder a análise espaço-temporal da cobertura vegetal e uso da terra na Interbacia do rio Paraguai Médio/MT, no período de 1991 a 2011 constataram que houve redução da área ocupada pela vegetação nativa e aumento da pastagem.

No município investigado a classe agricultura foi mapeada a partir de 1984, sendo representada quase que exclusivamente pelo cultivo da cana-de-açúcar. No intervalo de 1984 a 1993 a área aumentou para 3,34\%, enquanto que entre 1993 e 2003 decresceu, passando a ocupar 2,21\%. De 2003 até 2013 a classe aumentou sua área em aproximadamente 10\% (Tabela 04).

Este aumento na área ocupada está diretamente relacionado com o decréscimo da classe pastagem no ano de 2013, pois de acordo Simões (2009) normalmente a cana-de-açúcar é implantada em áreas que anteriormente eram ocupadas pelas pastagens. Dados do Censo Agropecuário de 2006 corroboram com o exposto, pois exibiu um aumento de 83,5\% das áreas de lavoura no país em relação ao Censo de 1996, enquanto que as pastagens diminuíram $3 \%$, o que evidencia a alteração de áreas de pastagens para áreas de produção agrícola (IBGE, 1998 e 2008)

O aumento da classe agricultura entre os anos de 2003 e 2013 está diretamente relacionado com a reabertura de uma usina em Mirassol D'Oeste em 2001, a qual havia sido declarada como falida. Azevedo Jr. et al. (2012) encontraram resultado semelhante nos municípios de Barra do Bugres/MT e Nova Olímpia/MT, cuja proximidade entre as áreas de plantio e as usinas impulsionaram a expansão canavieira.

A classe Reflorestamento, referente ao cultivo da teca (Tectona grandis L.), foi mapeada apenas em 2013, totalizando $1 \%$ da área municipal. A sua implantação é favorecida, de acordo com Rondon Neto et al. (1998) e Figueiredo et al. (2005), por sua madeira ser amplamente utilizada na fabricação de móveis de luxo e principalmente na construção naval, alcançando valores elevados. 
A Teca está sendo considerada na atualidade um ótimo investimento e seus povoamentos artificiais vem se destacando, principalmente os localizados em áreas tropicais, por favorecer o maior potencial de crescimento e produtividade (VAIDES et al., 2005). Segundo Kreitlow et al. (2014) a Teca foi introduzida em Cáceres na década de 60, e posteriormente se distribuiu para outras áreas do Estado e da região. Cabe ressaltar que a presença da classe Reflorestamento é importante do ponto de vista ambiental, pois são crescentes os pagamentos de serviços ambientais através de áreas reflorestadas.

A classe Influência urbana foi mapeada no ano de 1984, apresentando aumento constante no decorrer dos demais anos investigados. A expansão da classe está intimamente relacionada com o aumento populacional. Assim verifica-se que a população urbana cresceu aproximadamente 64\% (IBGE, 2013) no período de 1980 a 2010, o que implicou na construção de residências e aumento das atividades comerciais.

As áreas ocupadas pelas Massas d'água no decorrer dos anos estudados apresentaram diferentes percentuais (Tabela 4), sendo que em 2013 foi verificado a menor área ocupada pela classe durante o período estudado. Segundo Boin (2005) esta queda é resultado do desmatamento das áreas florestais que protegem estes ambientes.

Verificou-se que a condição ambiental de Mirassol D’Oeste é regular, entretanto os valores do ITA sofreram aumento conforme os anos analisados (Tabela 5).

O fator principal do aumento dos valores do ITA está relacionado ao aumento das áreas de pastagem que consequentemente a reduz a vegetação natural, na região a pecuária de corte extensiva é a atividade produtiva de maior relevância para economia. Segundo Dias-Filho (2014) a pecuária de corte extensiva é a atividade que apresenta baixo custo de mão de obra e tecnologia quando comparado à outras atividades, como a agricultura.

Tabela 5. Resultados do ITA para o município de Mirassol D’Oeste, nos anos de 1984, 1993, $2003,2013$.

\begin{tabular}{lrrrr}
\hline \multirow{2}{*}{ Classes temáticas } & \multicolumn{4}{c}{ ITA } \\
\cline { 2 - 5 } & $\mathbf{1 9 8 4}$ & $\mathbf{1 9 9 3}$ & $\mathbf{2 0 0 3}$ & $\mathbf{2 0 1 3}$ \\
\hline Floresta Aluvial & 0,03 & 0,09 & 0,08 & 0,09 \\
Savana Florestada & 0,37 & 0,21 & 0,12 & 0,10 \\
Floresta Estacional Decidual Submontana & 0,22 & 0,16 & 0,14 & 0,12 \\
Reflorestamento & 0,00 & 0,00 & 0,00 & 0,01 \\
Agricultura & 0,12 & 0,25 & 0,16 & 0,98 \\
Pastagem & 2,57 & 3,20 & 3,80 & 3,37 \\
Influência urbana & 0,04 & 0,06 & 0,06 & 0,06 \\
Massas d'água & 0,01 & 0,01 & 0,01 & 0,00 \\
\hline
\end{tabular}




\section{Total} $\begin{array}{llll}3,36 & 3,98 & 4,38 & 4,73\end{array}$

Fonte: Os Autores, 2017.

Embora a pastagem seja predominante, a agricultura aumentou ao longo dos anos devido a instalação de usinas para produção de açúcar e álcool. A produção sucroalcooleira vem sendo desenvolvida no município desde 1981, contribuindo para o incremento da econômica e incentivando o aumento e desenvolvimento da cultura de cana-de-açúcar no município (SCHEUER et al., 2016).

\section{Considerações Finais}

As formações vegetais das paisagens do município de Mirassol D’Oeste sofreram intensos processos de antropização nos últimos 29 anos, decorrente principalmente da inserção da pastagem para desenvolvimento da atividade pecuária bovina. A classe Pastagem apresentou elevado aumento até 2003, no entanto em 2013 constatou-se redução na mesma, decorrente principalmente da expansão da Agricultura, voltada para o cultivo de cana-deaçúcar. O Índice de Transformação Antrópica evidenciou que a antropização da paisagem tem aumentado, podendo, caso se mantenha o mesmo padrão de exploração, acelerar os processos de degradação dos componentes ambientais.

É necessário que seja contemplado no planejamento ambiental e priorizado na gestão do município as questões relativas a conservação do ambiente e, em alguns locais seja efetuada a recuperação das formações vegetais existentes, pois a posição espacial do município de Mirassol D’Oeste situado em área de tensão ecológica faz com que ocorra nos seus limites territoriais uma biodiversidade única, que está ameaçada em decorrência a fragmentação da vegetação para desenvolvimento das atividades produtivas rurais.

\section{Referencias Bibliográficas}

ALENCAR, A.; NEPSTAD, D.; MCGRATH, D.; MOUTINHO, P.; PACHECO, P.; DIAZ, M. D. C. V.; SOARES FILHO, B. Desmatamento na Amazônia: indo além da emergência crônica. Belém: Gráfica e Editora Super cores, 2004.85p.

ARRUDA, M. L. R. Estabelecimento e recuperação de pastagens no vale do Rio Doce. Informe Agropecuário, v. 13, n. 153/154, p. 23-25, 1988.

AZEVEDO JR. W. C.; DALLEMOLE, D.; FARIA, A. M. M. Análise locacional e impactos econômicos do segmento sucroalcooleiro em Mato Grosso. Revista Estudos do CEPE, v. 1, n. 35, p. 259-285, 2012.

BENEDETTI, A. C. P. Modelagem dinâmica para simulação de mudanças na cobertura 
florestal das Serras do Sudeste e Campanha Meridional do Rio Grande do Sul. 2010. 166

f. Tese (Doutorado em Engenharia Florestal) - Programa de Pós-Graduação em Engenharia Florestal, Universidade Federal de Santa Maria (UFSM), Santa Maria, 2010.

BERTRAND, G. Paisagem e geografia física global: esboço metodológico. Revista Ra'ega, v. 8, n. 1, p. 141-152, 2004.

BIERREGAARD, R. O.; LOVEJOY, T. E.; KAPOS, V.; SANTOS, A. A.; HUTCHINGS, R. W. The biological dynamics of tropical rain forest fragments. Bioscience, v. 42, n. 11, p. 859866, 1992.

BOHRER, C. B. A. Vegetação, paisagem e o planejamento do uso da terra. Geographia, v. 2, n. 4, p. 103-120, 2000.

BOIN, M. N. Áreas de preservação permanente: uma visão prática. 3 ed. São Paulo: Imprensa oficial, 2005. $861 \mathrm{p}$.

BORELLLI, D. L. AB'SÁBER, A. Problemas da Amazônia brasileira. Estudos Avançados, v. 19, n. 53, p. 7-35, 2005.

BRASIL. Ministério das Minas e Energia. Secretaria-geral. Projeto RADAMBRASIL. Folha SD 21 Cuiabá; geologia, geomorfologia, pedologia, vegetação e uso potencial da terra. Rio de Janeiro, 1982. $520 \mathrm{p}$.

BRASIL. Ministério do Meio Ambiente. Projeto Probio, Avaliação e Ações para a Conservação da Biodiversidade nos Biomas Cerrado e Pantanal, 2004. Disponível em: <http://www.mma.gov.br/estruturas/sbf_chm_rbbio/_arquivos/Sumario\%20Cerrado-

Pantanal.pdf>. Acesso em: 25de outubro 2014.

CABACINHA, C. D.; CASTRO, S. S. GONÇALVES, D. A. Análise da estrutura da paisagem da alta bacia do rio Araguaia na savana brasileira. Floresta, v.40, n. 4, p. 675-690, 2010.

CÂMARA, G.; SOUZA, R. C. M.; FREITAS, U. M.; GARRIDO, J. SPRING: Integrating remote sensingand GIS byobject-oriented data modeling. Computers \& Graphics, v. 20, n. 3, p. 395 - 403, 1996.

CAMARGO, A. M. M. P.; CASER, D. V.; CAMARGO, F. P.; OlivetTe, M. P. A. Dinâmica e tendência da expansão da cana-de-açúcar sobre as demais atividades agropecuárias, Estado de São Paulo, 2001- 2006. Informações Econômicas, v. 38, n. 3, p. 47-66, 2008.

CARNIELLO, M. A.; SILVA, R. S.; CRUZ, M. A. B.; GUARIM NETO, G. Quintais urbanos de Mirassol D'Oeste-MT, Brasil: uma abordagem etnobotânica. ActaAmaz, v.40, n.3, p.451470, 2010.

CEBALHO, D. A.; MIRANDA, M. R. S.; MACHADO, T. S.; NEVES, S. M. A. S.; NEVES, R. J. Análise do uso da terra e da estrutura da paisagem do município de Porto Esperidião/MT. Revista Ibero-Americana de Ciências Ambientais, número especial, p. 117, 2017.

COCCO, J.; RIBEIRO, H. V.; GALVANIN, E. A. S.; NASCIMENTO, D. L. Análise e previsões das ações antrópicas para a bacia do rio do Sangue - Mato Grosso/Brasil. Revista de Estudos Sociais, v. 17, n. 34, p. 52-63, 2015.

COHEN, J. A. Coefficient of agreement for nominal scales. Educational and Psychological Measurement, v. 20, n. 1, p. 37-46, 1960.

CUNHA, S. B.; GUERRA, A. J. T. A Questão ambiental: diferentes abordagens. Rio de Janeiro: Bertrand Brasil, 2003. 248p.

CRUZ, C. B. M.; TEIXEIRA, A. J. A.; BARROS, R. S.; ARGENTO, M. S. F.; MAYR, L. M.; MENEZES, P. M. L. Carga antrópica da bacia hidrográfica da Baía de Guanabara. In: Simpósio Brasileiro de Sensoriamento Remoto, Santos, Brasil, INPE. 1998; 9:99-109. Anais ... SBSR, 1998.

DANIEL, H.; TARSITANO, M. A. A.; ZANON, N. B.; ARAUJO, R. S.; FERNANDES, W. 
B. Caracterização da expansão da cultura da cana-de-açúcar e dos tipos de contratos realizados nas regionais de Jales e General Salgado do estado de São Paulo. In: Congresso Brasileiro de Economia, Administração e Sociologia Rural, 47, 2009, Porto Alegre. Anais...Porto Alegre: SOBER/URGS, 2009. p. 1-16.

DIAS-FILHO, M. B. Diagnóstico das pastagens no Brasil. Belém: Embrapa Amazônia Oriental, 2014. 38p.

ESRI. ArcGIS Desktop: release 9.2. Redlands, CA: Environmental Systems Research Institute, 2007.

FAO. Forest Resources Assessment 2010: Main Report. Rome: FAO, 2011. p.179.

FEARNSIDE, P. M. A floresta Amazônia nas mudanças globais. Manaus: Instituto Nacional de Pesquisas da Amazônia, 2003. 134p.

FIGUEIREDO E. O.; OLIVEIRA A. D.; SCOLFORO J. R. S. Análise econômica de povoamentos não desbastados de Tectona grandis L.f., na microrregião do baixo Rio Acre. Cerne, v.11, n.4, p.342-353, 2005.

FIORO, P. R.; DEMATTÊ, J. A. M.; SPAROVEK, G. Cronologia e impacto ambiental no uso da terra na Microbacia Hidrográfica do Ceveiro, em Piracicaba, SP. Pesq. Agropec. Bras, v. 35, n. 4, p. 671-679, 2000.

GUIMARÃES, P.R.B. Análise de Regressão. In: Guimarães, P.R.B. Métodos Quantitativos Estatísticos. IESDE Brasil S.A., Curitiba. 245p. 2008.

IBGE. Censo agropecuário 1995-1996, 1998. Disponível em: <http://www.ibge.gov.br/home/estatistica/economia/agropecuaria/censoagro/1995_1996/defa ult.shtm> Acesso em: 27 de dezembro de 2014.

IBGE. Instituto Brasileiro de Geografia e Estatística. Censo agropecuário de 2006, 2008. Disponível em: $<$ http://www.sidra.ibge.gov.br/bda/pesquisas/ca/default.asp?o=2\&i=P\#8> Acesso em: 27 de dezembro de 2014.

IBGE. Instituto Brasileiro de Geografia e Estatística. Manual técnico da vegetação brasileira. 3 ed. Rio de Janeiro: IBGE, 2012. 45-168 p.

IBGE. Instituto Brasileiro de Geografia e Estatística. IBGE Cidades. Rio de Janeiro: IBGE, 2013. Disponível em:www.cidades.ibge.gov.br. Acesso em: 25 de agosto de 2014.

IGLIORI, D. C. Economia espacial do desenvolvimento e da conservação ambiental: uma análise sobre o uso da terra na Amazônia. Ciência e Cultura, v. 58, n. 1, p. 29-33, 2006.

JANSEN, L. J. M. e GREGORIO, A. Parametric land cover and land use classifications as tools for environmental change detection. Agriculture Ecossystems e Environment, v. 91, n. $1-3$, p. 89-100, 2002.

JENSEN, J. R. Introductory digital image processing a remote sensing perspective. $2 \mathrm{ed}$. New Jersey: Prentice Hall, 1996.316 p.

KREITLOW, J. P.; NEVES, S. M. A. S.; NEVES, R. J.; SERAFIM, M. E. Avaliação geoambiental das terras do município brasileiro de Cáceres para o cultivo de teca. R. Ra'eGa, v. 31, n. 2, p. 53-68, 2014.

LANDIS, J. R.; KOCH, G. G. The measurement of observer agreement for categorical data. Biometrics, v. 33, n. 1, p. 159-174, 1977.

LAURANCE, W. L.; ALBERNAZ. A. K. M.; FEARNSIDE, P. M.; VASCONCELOS, H; FERREIRA, L. V. Deforestation in Amazonia. Science, v. 304, n. 5674, p. 1109-1111, 2004.

LÉMECHEV. T. On hydrological heterogeneity catchment morphology and catchment response. Journal of Hydrology, v.100, p. 357- 375, 1982.

LIMA, I. B. T.; BARBOSA, C. C.; NOVO, E. M. L. M.; CARVALHO, J. C.; STECH, J. L. Localização de áreas de monitoramento telemétrico em ambientes aquáticos da Amazônia. ActaAmaz., v. 36, n. 3, p. 331 - 334, 2006.

LOVEJOY, T. E.; BIERREGAARD, R. O.; RYLANDS, A. B.; MALCOLM, J. R.; QUINTELA, C. E.; HARPER, L. H.; BROWN, K. S.; POWELL, A. H.; POWELL, G. V. N.; 
SCHUBART, H. O. R.; HAYS, M. B. Edge and other effects of isolation on Amazon forest fragments. In: SOULÉ, M. E. Conservation Biology: the science of scarcity and diversity. Sinauer, Sunderland, Massachusetts, USA. 1986. p. 257-285.

MACHADO, R. B.; RAMOS NETO, M. B.; PEREIRA, P. G. P.; CALDAS, E. F.; GONÇALVES, D. A.; SANTOS, N. S.; TABOR, K.; STEININGER, M. Estimativas de perda da área do Cerrado brasileiro. Conservação Internacional. Brasília, DF. 2004. Disponível em: <http://www.conservation.org.br/arquivos/RelatDesmatamCerrado.pdf >. Acesso em: 13 de setembro de 2014.

MAEDA, E. E.; FORMAGGIO, A. R.; SHIMABUKURO, Y. E. Análise histórica das transformações da floresta Amazônica em áreas agrícolas na bacia do rio Suia-miçu. Sociedade \& Natureza, v.20, n.1, p. 5-24, 2008.

MARGUlis, S. Causas do desmatamento da Amazônia brasileira. Brasília: Estação Gráfica. 2003. 100p.

MARTORANO, L. G.; TAVARES, H.; SCHULER, A.; MEIRELlES, M. S. P.; VALENCIA, L. I. O.; SANTOS, F. L. de O.; LISBOA, L.; TEIXEIRA, F. A.; PEREIRA, S.; FERRAZ, R. D.; MONTEIRO, J. G.; TURETTA, A. P.; COUTINHO, H. L. SIAT-TTC design and architecture, Sustainability Impact Assessment Tool prototype: demonstration tool at TTC-level, for MERCOSUR. Rio de Janeiro: Embrapa Solos, 2009. $126 \mathrm{p}$.

MATEO, J. Geoecologia de los paisajes. Mérida: Edit. ULA, Monografia, 1991.

MATO GROSSO (Estado). Levantamento de reconhecimento de baixa intensidade dos solos do Estado de Mato Grosso. Cuiabá: SEPLAN, 2009. 121p.

MATO GROSSO (Estado). Secretaria de Estado de Planejamento e Coordenação Geral.Plano de Longo Prazo de Mato Grosso: macro-objetivos, metas globais, eixos estratégicos e linhas estruturantes. In: PRADO, J. G. B.; BERTCHIELI, R.; OLIVEIRA, L. G. (Orgs). Plano de Longo Prazo de Mato Grosso. Cuiabá/MT: Central de Texto, v. IV, 2012. 108p. Disponível em: <http://www.seplan.mt.gov.br/mt20/mt20.htm>. Acesso em: 28 de agosto de 2014.

MUlleR, M. M. L.; GUIMARÃES, M. F.; DESJARDINS, T.; MARTINS, P. F. S. Degradação de pastagens na Região Amazônica: propriedades físicas do solo e crescimento de raízes. Pesq. Agropec. Bras., v. 36, n. 11, p. 1409-1418, 2001.

NEVES, S. M. A. S.; KREITlOW, J. P.; SILVA, J. S. V.; MIRANDA, M. R. S.; VENDRAMINI, W. J. Pressão antrópica na paisagem de Mirassol D’Oeste/MT, Brasil: subsídios para o planejamento ambiental municipal. Ciência Geográfica, v. 21, n. 1, p. 141-155, jan./dez., 2017.

PESSOA, S. P. M.; GALVANIN, E. A. S.; KREITLOW, J.P.; NEVES, S. M. A. S.; NUNES, J. R. S.; ZAGO, B. W. Análise espaço-temporal da cobertura vegetal e uso da terra na Interbacia do Rio Paraguai Médio-MT, Brasil. Revista Árvore, v.37, n.1, p.119-128, 2013.

PNUD. Programa das Nações Unidas para o Desenvolvimento. Atlas de Desenvolvimento Humano. Índice de Desenvolvimento Humano (IDH) dos municípios brasileiros. Disponível em: <www.pnud.org.br>. Acesso em: 26 de agosto de 2013.

RAVIKANTH, G.; SHAANKER, R. U.; GANESHAIAH, K. N. Conservation status of forests in India: A cause for worry? Journal of the Indian Institute of Science, v. 80, n. 6, p. 591-600, 2000.

RIVERO, S.; ALMEIRA, O.; ÁVILA, S.; OLIVEIRA, W. Pecuária e desmatamento: uma análise das principais causas diretas do desmatamento na Amazônia. Nova economia, v. 19, n. 1, p. 41-66, 2009.

RONDON NETO, R. M.; MACEDO, R. L. G.; TSUKAMOTO FILHO, A. A. Formação de povoamentos florestais com Tectonagrandis L.f. (Teca). Boletim Técnico, v. 7, n. 33, p. 129, 1998.

ROSA, R. Introdução ao sensoriamento remoto. 6 ed. Uberlândia/MG: EDUFU, 2007. 
248p.

SANTOS, D.; BAHIA, V. G.; TEIXEIRA, W. G. Queimadas e erosão do solo. Informe Agropecuário, v. 16, n. 176, p. 62-68, 1992.

SEABRA, V. S.; CRUZ, C. M. Mapeamento da dinâmica da cobertura e uso da terra na Bacia Hidrográfica do Rio São João, RJ. Sociedade \&Natureza, v. 25. n. 2, p. 411-426, 2013.

SIMÕES, J. Estudo inédito, com base em imagens de satélite, mostra avanço sobre pastagens eoutroscultivos; florestas são pouco atingidas. Inovação Unicamp, 31 agosto 2009.

Disponível

em:

<http://www.inovacao.unicamp.br/report/noticias/index.php?cod=588>. Acesso em: $26 \mathrm{de}$ julho 2014.

SCHWENK, L. M.; CRUZ, C. B. M. Conflitos socioeconômicoambientais relativos ao avanço do cultivo da soja em áreas de influência dos eixos de integração e desenvolvimento no Estado de Mato Grosso. Acta Scientarium Agronomy. v. 30, p.501-511. 2008.

SCHEUER, J. M.; LUPERINI, V. H.; NEVES, S. M. A. S. Influências populacionais e socioeconômicas das destilarias Cooprocami/Cooperb II em Mirassol d'oeste, Mato Grosso. Faz Ciência, vol. 18, n. 27, p. 56-75. 2016.

TERBORGH, J.; LOPES, L.; TELLO, J.; YU, D.; BRUNI, A. R. Transitory states in relaxing ecosystems of land bridge islands. In: W. F. LAURANCE, R. O. BIERREGAARD. Tropical Forest Remnants: ecology, management, and conservation of fragmented landscape. Chicago: University of Chicago Press, 1997. p. 256-274.

TILMAN, D.; MAY, R. M.; LEHMAN, C. L.; NOWAK, M. A. Habitat destruction and the extinction debt. Nature, v. 72, n. 3, p. 65-66. 1995.

TSUKAMOTO FILHO, A. A.; SILVA, M. L.; COUTO, L.; MÜLLER, M.D. Análise econômica de um plantio de teca submetido a desbastes. Revista Árvore, v. 27, n. 4, p. 487 494, 2003.

TUCKER, C. J.; GRANT, D. M.; DYKSTRA, J. D. NASA's Global Orthorectified Landsat Data Set. Photogrammetric Engineering \& Remote Sensing, v. 70, n. 3, p. 313-322, 2004.

VAIDES, E.; UGALDE, L.; GALLOWAY, G. Crecimiento y productividad de teca en plantaciones forestales jóvenes en Guatemala. Recursos Naturales y Ambiente, v. 1, n. 4647, p.137-145, 2005.

VITOUSEK, P.M. et al. Introduced species: A significant component of human-caused global change. New Zealand Journal of Ecology, v. 21, n. 1, p. 1 - 16, 1997.

Recebido em 09 de outubro de 2017.

Aceito em 05 de março de 2018. 